\title{
Measuring room-temperature intrinsic multiferroic properties by excluding the secondary magnetic inclusion contribution
}

\author{
Shujie Sun ${ }^{1}$, Changhui Liu ${ }^{1}$, Ranran Peng ${ }^{1,2 *}$, Zhengping Fu ${ }^{1,2}$ and Yalin $\mathrm{Lu}^{1,2,3 *}$
}

\begin{abstract}
The assertion that a new material could become a potential single-phase and room-temperature functioning multiferroic material may be confounded by the presence of minor amount of secondary magnetic inclusions, especially in the Aurivilliustype material system. In this study, we demonstrated that the derivative thermo-magneto-gravimetry (DTMG) technique can be a sensitive tool to identify and quantify the magnetic secondary phases in the $\mathrm{Bi}_{7} \mathrm{Fe}_{2.25} \mathrm{Co}_{0.75} \mathrm{Ti}_{3} \mathrm{O}_{21}$ ceramic, which shows the potential to become a single-phase multiferroic material. The accuracy of this DTMG measurement experimentally reaches to $\sim 0.5 \mathrm{wt} . \%$, far below the detection limit of the traditional X-ray diffraction. The impurity identified in the specimen is the ferrimagnetic $\mathrm{CoFe}_{2} \mathrm{O}_{4}$ spinel phase with an amount of $\sim 3.6 \mathrm{wt} . \%$. Significantly, the room-temperature intrinsic magnetism of the ceramic was measured, which is sorely from the main phase.
\end{abstract}

\section{INTRODUCTION}

Seeking a single-phase and room-temperature functional multiferroic material has been a long-standing challenge, although it is of great importance to understand fundamental physics and to explore the potential application [1-3]. As candidates with the potential to become a single-phase multiferroic material exhibiting simultaneous coexistence of ferroelectric (FE) and ferromagnetic (FM) orders, layer-structured oxides with a general formula of $\mathrm{Bi}_{n+1} \mathrm{Fe}_{n-3} \mathrm{Ti}_{3} \mathrm{O}_{3 n+3}$ ( $n$ denotes an integer corresponding to the number of the sandwiched perovskite layers) have attracted increasing attention in recent years [4-6]. Recently, numerous studies regarding to the realization of a remarkable coexistence of FE and FM properties at room temperature (RT) from these layered oxides by chemical modifications, e.g., various A- or B-site doping, have been reported [7-11]. However, the question whether the multiferroic responses in these materials are intrinsic from the main phase or from the secondary phase formed during the sample preparation is still under debate $[12,13]$. Therefore, some new methods or sensible techniques have to be developed to identify intrinsic multiferroic responses in studying such complicated layered oxides.

Normally, the X-ray diffraction (XRD) method provides a direct way to detect a secondary phase in powders, thin films or bulk ceramics, but this method cannot deal with the case that the weight ratio of the impurity is below a certain critical level ( $\sim \mathrm{wt} . \%$, for example). Scanning electron microscopy (SEM) and/or electron backscatter (EBS) coupled with an energy dispersive X-ray spectroscopy (EDX/ EDS) [14] can also offer useful information to detect the possible existence of secondary phase, but they are limited to very small sample volumes [12]. Interestingly, the derivative thermo-magneto-gravimetry (DTMG) technique [15], using the principle that magnetic transition affects weight, is very promising for tracing various subtle changes of the magnetic property $v s$. temperature, especially the magnetic contributions.

In this study, we applied the DTMG technique to quantitatively discern the content and the magnetic contribution of the possible ferromagnetic/ferrimagnetic inclusions in a $\mathrm{Bi}_{7} \mathrm{Fe}_{2.25} \mathrm{Co}_{0.75} \mathrm{Ti}_{3} \mathrm{O}_{21}$ (BFCT) layered oxide ceramic, which is chosen because of its relatively stronger FE and FM properties observed at RT [16]. The impurity identified in BFCT ceramic is $\mathrm{CoFe}_{2} \mathrm{O}_{4}$ with a weight ratio of $\sim 3.6 \%$ and its magnetic contribution to weight loss is $\sim 15 \%$. Significantly, it was testified that this layered oxide has good magnetic response at RT, which is intrinsic. Our experimental results also suggested that the measurement accuracy of DTMG method can reach to $\sim 0.5 \mathrm{wt} . \%$, far below the detection limit of XRD. In short, this DTMG method is

\footnotetext{
${ }^{1}$ CAS Key Laboratory of Materials for Energy Conversion, Department of Materials Science and Engineering, University of Science and Technology of China, Hefei 230026, China

${ }^{2}$ Synergetic Innovation Center of Quantum Information \& Quantum Physics, University of Science and Technology of China, Hefei 230026, China

${ }^{3}$ National Synchrotron Radiation Laboratory, University of Science and Technology of China, Hefei 230026, China

*Corresponding authors (emails: yllu@ustc.edu.cn (Lu Y); pengrr@ustc.edu.cn (Peng R))
} 
powerful and effective to detect and quantify the ferromagnetic/ferrimagnetic response, which can be easily applied to other magnetic materials and be of great help to explore new magnetic materials.

\section{EXPERIMENTAL SECTION}

\section{Materials synthesis}

Polycrystalline BFCT was prepared by a modified Pechini method. Detailed synthesis process was as follows: $\mathrm{Bi}\left(\mathrm{NO}_{3}\right)_{3} \cdot 5 \mathrm{H}_{2} \mathrm{O}, \quad \mathrm{Fe}\left(\mathrm{NO}_{3}\right)_{3} \cdot 9 \mathrm{H}_{2} \mathrm{O}, \quad \mathrm{Co}\left(\mathrm{NO}_{3}\right)_{2} \cdot 6 \mathrm{H}_{2} \mathrm{O}$ and $\mathrm{Ti}\left(\mathrm{OC}_{4} \mathrm{H}_{9}\right)_{4}$ according to the stoichiometric ratio of the BFCT were dissolved into $\mathrm{HNO}_{3}$ as precursors. $\mathrm{C}_{6} \mathrm{H}_{8} \mathrm{O}_{7} \cdot \mathrm{H}_{2} \mathrm{O}$ and ethylene diamine tetraacetic acid (EDTA) were added to the solution as the coordinating agents. Then $\mathrm{NH}_{3} \cdot \mathrm{H}_{2} \mathrm{O}$ was added dropwise into the solution to adjust the $\mathrm{pH}$ value to $6-7$, and the precursors formed a stable transparent solution. Then, the precursor sol was heated until combustion inside the crucible. Afterwards, the product was calcined at $1025 \mathrm{~K}$ for $2 \mathrm{~h}$ to remove organic residues. The obtained powders were pressed into pellets and then were sintered in a hot-pressed furnace at $1153 \mathrm{~K}$ for $3 \mathrm{~h}$, under the atmosphere of mixed $\mathrm{Ar} / \mathrm{O}_{2}$ gas and a pressure of $10 \mathrm{MPa}$ (Materials Research Furnaces Inc., Suncook, NH). The powders of $\mathrm{BiFe}_{0.75} \mathrm{Co}_{0.25} \mathrm{O}_{3}$ and $\mathrm{CoFe}_{2} \mathrm{O}_{4}$, the possible impurity phases, were also synthesised by the same method. $\mathrm{Co}_{3} \mathrm{O}_{4}$ (analytic pure) and $\mathrm{Fe}_{3} \mathrm{O}_{4}$ (analytic pure) powders were used as reference samples.

\section{Characterization and measurements}

XRD patterns of the samples were obtained by using a TTR-III X-ray diffractometer with $\mathrm{Cu}-\mathrm{Ka}$ radiation $(\lambda=$ $1.5418 \AA$ ). Rietveld refinements of the XRD pattern were made using GSAS software. Magnetic properties were characterized by vibrating sample magnetometer (VSM) option of the Quantum Design physical property measurement system (PPMS, USA). Thermo-magneto-gravimetry (TMG) measurements were realized using Thermo-gravimetric Analysis (TGA Q5000IR, USA) to measure the weight of a sample as a function of testing temperatures at an applied magnetic field. The TMG measurements were performed in nitrogen atmosphere at a heating rate of $20 \mathrm{~K}$ or $5 \mathrm{~K} \mathrm{~min}^{-1}$ with or without a $0.02 \mathrm{~T}$ applied magnetic field. DTMG gave the derivative weight of a sample with respect to temperatures. For the ferroelectric measurements, the pellets were polished to a thickness of $\sim 0.3 \mathrm{~mm}$ and then Ag was evaporated on both sides as electrodes. The ferroelectric measurements were conducted using a Precision LC ferroelectric analyzer (Radiant Technology, USA) at an applied frequency of $10 \mathrm{~Hz}$.

\section{RESULTS AND DISCUSSION}

Fig. 1a shows the XRD patterns of the BFCT powder and some reference samples, such as $\mathrm{BiFe}_{0.75} \mathrm{Co}_{0.25} \mathrm{O}_{3}, \mathrm{CoFe}_{2} \mathrm{O}_{4}$, $\mathrm{Fe}_{3} \mathrm{O}_{4}$ and $\mathrm{Co}_{3} \mathrm{O}_{4}$. The Rietveld refinement of BFCT XRD pattern was performed using GSAS software, as shown in Fig. 1a. The pattern was refined with the orthorhombic lattice space group of $A 2_{1} a m$ and the observed peaks are all in good accordance with the standard powder diffraction data for the four-layer $\mathrm{Bi}_{5} \mathrm{FeTi}_{3} \mathrm{O}_{15}$ (JCPDS, No.82-0063). The lattice parameters turn out to be $a=5.462 \AA, b=5.434 \AA$, $c=41.115 \AA\left(R_{\mathrm{p}}=12.6 \%\right)$. According to the refinement results, the quantity of the possible impurity phase, if it exists, should be below XRD instrumental resolution. Keeney et al. $[13,17]$ had reported that the magnetic secondary phase from Co substituted Aurivillius-type multiferroic thin film is a $\mathrm{CoFe}_{2} \mathrm{O}_{4}$ type spinel phase. However, for our ceramic, it is very difficult to distinguish the possible impurity phases from the main Aurivillius phase by the XRD analysis, because the positions of the main peaks of the possible magnetic inclusions (e.g., $\mathrm{CoFe}_{2} \mathrm{O}_{4}$ ) and the part peaks of the Aurivillius phase appear to overlap, as shown in Fig. 1a.
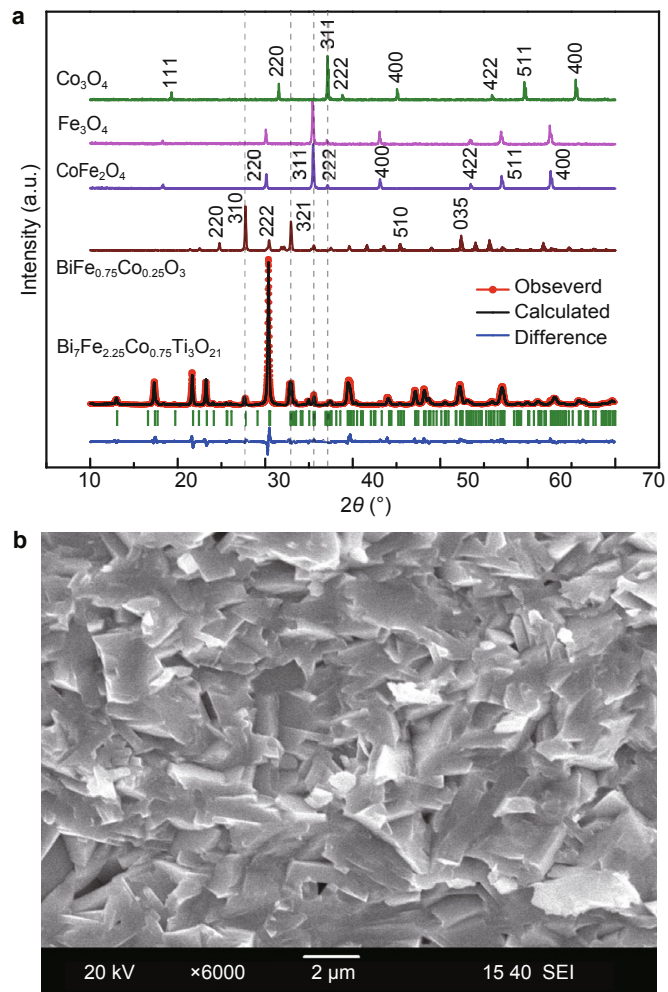

Figure 1 Characterizations of BFCT polycrystalline ceramic. (a) Observed (red solid circles), calculated (black solid lines) and difference (blue solid line) XRD patterns of BFCT. No second phase is detected. XRD patterns of $\mathrm{BiFe}_{0.75} \mathrm{Co}_{0.25} \mathrm{O}_{3}, \mathrm{CoFe}_{2} \mathrm{O}_{4}, \mathrm{Fe}_{3} \mathrm{O}_{4}$ and $\mathrm{Co}_{3} \mathrm{O}_{4}$ are shown for reference. (b) SEM image of the BFCT ceramic. 
The SEM image of the BFCT was taken from fresh fracture surface and shown in Fig. 1b. The ceramic prepared using the hot-press sintering technique is very dense with well compact grains and its relative density determined by the Archimedes method is $~ 93 \%$.

$M-H$ hysteresis loops of the BFCT measured at different temperatures are shown in Fig. 2a, and the remnant magnetization $\left(2 M_{\mathrm{r}}\right)$ and the saturation magnetization $\left(M_{\mathrm{s}}\right)$ extracted from these hysteresis loops are illustrated in Fig. $2 \mathrm{~b}$. $2 M_{\mathrm{r}}$ and $M_{\mathrm{s}}$ decrease as the testing temperature increases, but still maintain acceptable values when the temperature reaches to $373 \mathrm{~K}$, indicating a fairly $\mathrm{RT}$ operation stability for device applications. It is noted that $2 M_{\mathrm{r}}$ and $M_{\mathrm{s}}$ of the BFCT at RT are approximate 2.4 and 7.7 emu $\mathrm{g}^{-1}$, respectively. This $2 M_{\mathrm{r}}$ value is about three orders of magnitude higher than that of $\mathrm{Bi}_{7} \mathrm{Fe}_{3} \mathrm{Ti}_{3} \mathrm{O}_{21}\left(\sim 2.67\right.$ memu g $\left.{ }^{-1}\right)$ [18] and $\mathrm{Bi}_{5} \mathrm{Fe}_{0.5} \mathrm{Co}_{0.5} \mathrm{Ti}_{3} \mathrm{O}_{15}\left(\sim 7.8\right.$ memu g $\left.{ }^{-1}\right)$ [11]. From Fig. 2a, the material's Curie temperature $\left(T_{\mathrm{C}}\right)$ can be deduced among 673-753 K, which is much higher than the RT. Lu et al. [19] had reported an exchange interaction (e.g., exchange bias) between two magnetic phases can also provide a sensitive
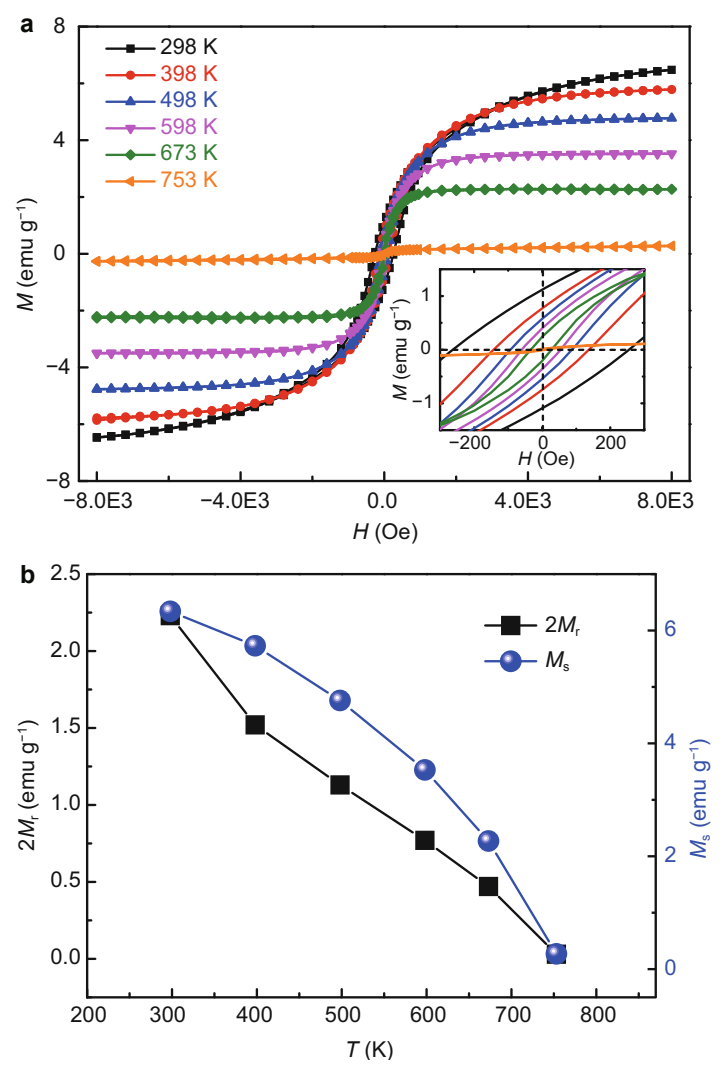

Figure 2 Room temperature magnetic property of the BFCT ceramic. (a) $M-H$ hysteresis loops of BFCT at 298, 398, 498, 598, 673 and $753 \mathrm{~K}$. The inset shows an enlarged central region. (b) $2 M_{\mathrm{r}}$ and $M_{\mathrm{s}}$ of BFCT $v s$. temperatures. way to identify the ferrimagnetic phase. But this method requires a ferrimagnet/antiferromagnetic interface formed at the grain surface, and it is hardly to quantify the magnetic secondary phase. In addition, no distortion of the $M-H$ hysteresis loops was observed in our ceramic sintered at $1153 \mathrm{~K}$, suggesting that the exchange interaction between the main phase and the magnetic secondary inclusions (if it exists) is very weak. Therefore, new methods or sensible techniques have to be developed to identify and quantify the magnetic secondary phases.

According to the above results of magnetic measurements, we deduced that the decisive magnetic second phase inclusion, if it exists, may be the $\mathrm{CoFe}_{2} \mathrm{O}_{4}$ type spinel phase. The reasons may include as follows: 1) $T_{\mathrm{C}}$ of $\mathrm{CoFe}_{2} \mathrm{O}_{4}$ ferrite particles is near $\sim 700 \mathrm{~K}$ [20], and $2 M_{\mathrm{r}}$ and $M_{\mathrm{s}}$ of bulk $\mathrm{CoFe}_{2} \mathrm{O}_{4}$ at RT are about 53 and $79 \mathrm{emu} \mathrm{g}^{-1}$ [21] (higher than the values of $\mathrm{CoFe}_{2} \mathrm{O}_{4}$ ferrite particles, $2 M_{\mathrm{r}}$ $\sim 29 \mathrm{emu} \mathrm{g}^{-1}$ and $M_{\mathrm{s}} \sim 62 \mathrm{emu} \mathrm{g}^{-1}$ ), respectively, meaning that a low content can make a big magnetic response; 2 ) $\mathrm{Co}_{3} \mathrm{O}_{4}$ is an antiferromagnet $\left(T_{\mathrm{N}} \sim 30 \mathrm{~K}\right)[22]$ and the $T_{\mathrm{C}}$ of $\mathrm{Fe}_{3} \mathrm{O}_{4}$ was reported a value of $\sim 875 \mathrm{~K}$ [23], which are both beyond $673-753 \mathrm{~K}$ limits; 3 ) because the BFCT was calcined at $1023 \mathrm{~K}$ and sintered at $1153 \mathrm{~K}$, it seems that the $\mathrm{Fe}_{3} \mathrm{O}_{4}$, if it exists, should be oxidized to $\alpha-\mathrm{Fe}_{2} \mathrm{O}_{3}$ (normally, $\mathrm{Fe}_{3} \mathrm{O}_{4}$ initially forms $\gamma-\mathrm{Fe}_{2} \mathrm{O}_{3}$ at about $450 \mathrm{~K}$, and then changes to $\alpha-\mathrm{Fe}_{2} \mathrm{O}_{3}$ at about $\left.623 \mathrm{~K}[24]\right)$. Yet, $\alpha-\mathrm{Fe}_{2} \mathrm{O}_{3}$ is a weak ferromagnetic material at $\mathrm{RT}$ and its magnetization is less than 1 emu $\mathrm{g}^{-1}[25]$; 4) the $\mathrm{BiFe}_{0.75} \mathrm{Co}_{0.25} \mathrm{O}_{3}$ has the magnetic property $\left(2 M_{\mathrm{r}} \sim 9 \mathrm{emu} \mathrm{g}^{-1}\right.$ and $\left.M_{\mathrm{s}} \sim 13 \mathrm{emu} \mathrm{g}^{-1}\right)$ in the same order with that of the BFCT, implying that a low content of $\mathrm{BiFe}_{0.75} \mathrm{Co}_{0.25} \mathrm{O}_{3}$ only has a little small magnetic response. Therefore, we will focus our discussion on the ferromagnetic second phase $\mathrm{CoFe}_{2} \mathrm{O}_{4}$.

Fig. 3 shows thermo-gravimetric (TG) curves of

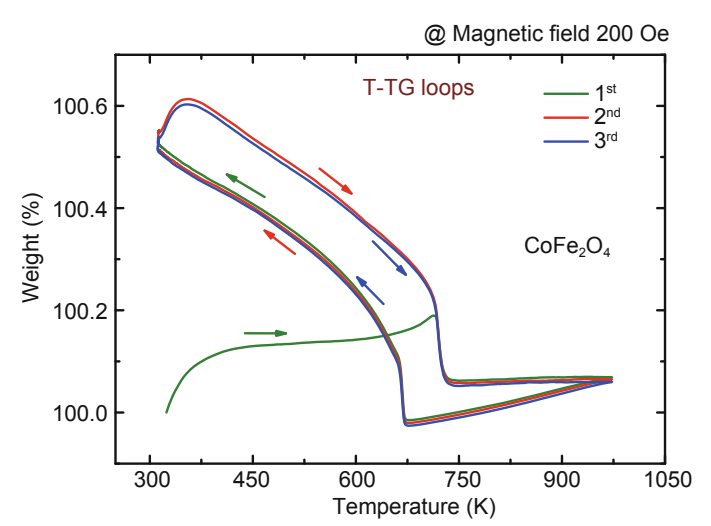

Figure 3 Thermo-gravimetric curves of $\mathrm{CoFe}_{2} \mathrm{O}_{4}$ at three times thermo-cycling measurements under a $0.02 \mathrm{~T}$ applied magnetic field with a heating/cooling rate of $20 \mathrm{~K} \mathrm{~min}^{-1}$. 
$\mathrm{CoFe}_{2} \mathrm{O}_{4}$ at three times thermo-cycling measurements under a $0.02 \mathrm{~T}$ applied magnetic field with a heating/cooling rate of $20 \mathrm{~K} \mathrm{~min}^{-1}$. A T-TG loop is clearly observed. What's more, this loop can be well repeated by multi-measurements, indicating that the TMG technique has a good response to magnetic materials. The curves measured at the heating processes and the cooling processes do not overlap each other, indicating a thermal hysteresis. We also note that a sharp weight loss of $\mathrm{CoFe}_{2} \mathrm{O}_{4}$ occurs at approximately $721 \mathrm{~K}$ in the TG curve at heating processes, however, a sharp weight gain occurs at approximately $670 \mathrm{~K}$ at cooling processes. These features imply that the ferrimagnetic
$\mathrm{CoFe}_{2} \mathrm{O}_{4}$ phase may be identified by the sharp weight loss/ weight gain using the TMG technique in Aurivillius-type multiferroic material, if it is assumed that it does not interact with the Aurivillius phase matrix, in view of considerable evidences of phase separation between $\mathrm{CoFe}_{2} \mathrm{O}_{4}$ spinel phase and perovskite structures such as $\mathrm{BiFeO}_{3}[26]$, $\mathrm{BaTiO}_{3}$ [27] and $\mathrm{PbTiO}_{3}$ [28].

Fig. 4 shows weight loss and DTMG curves of the BFCT at the heating processes through seven times thermo-cycling measurements. The 1 st-4th conditions were measured at the heating rate of 20 or $5 \mathrm{~K} \mathrm{~min}^{-1}$ under $0.02 \mathrm{~T}$, and the 5 th -7 th conditions were measured at the heating

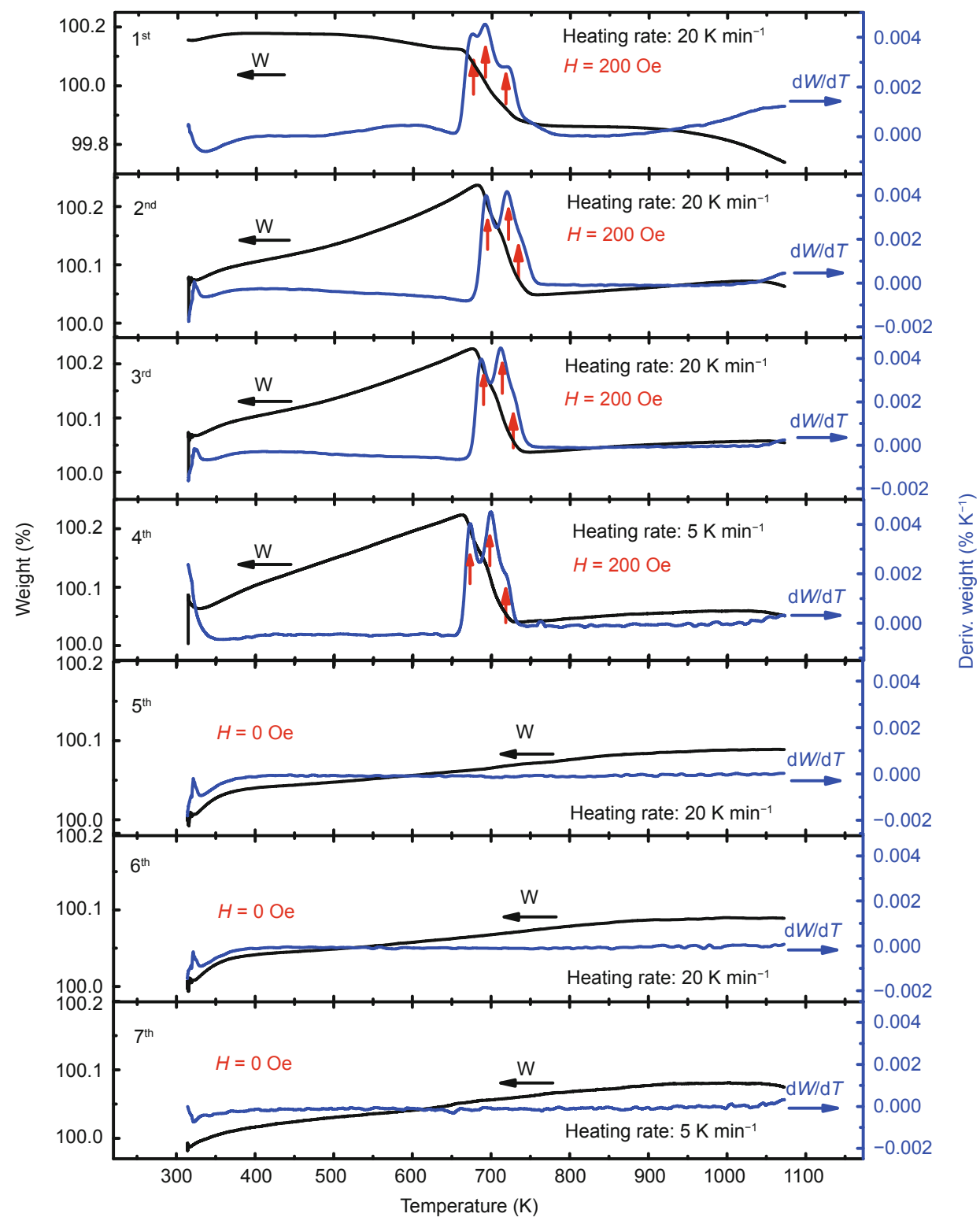

Figure 4 Thermo-gravimetric and the DTMG curves of the heating processes of the BFCT through seven times thermo-cycling measurements with/ without applied magnetic field. All the cooling processes are at the rate of $20 \mathrm{~K} \mathrm{~min}^{-1}$ without applied magnetic field. 
rate of 20 or $5 \mathrm{~K} \mathrm{~min}^{-1}$ under $0 \mathrm{~T}$. All cooling processes (no shown) are at the cooling rate of $20 \mathrm{~K} \mathrm{~min}^{-1}$ without applied magnetic field. The 1st TG curve is different from that of the 2 nd and $3 \mathrm{rd}$, due to the possible existence of water, pores or specific distribution of magnetic domains in initial sample. The 2 nd -4 th curves have the similar trends, indicating that the phenomena can be well repeated. However, the different heating rates result in a small shift of the peaks from the DTMG curves, indicating the existence of a thermal hysteresis which is consistent with above discussion. From the 1 st -4 th measurements, we can find that the FM-paramagnetic (PM) transition of the sample has a broad temperature range, about $660-740 \mathrm{~K}$, in the TG curves, and this transition consists of about three peaks in DTMG curves. What's more, the weight loss temperature of $\mathrm{CoFe}_{2} \mathrm{O}_{4}(\sim 721 \mathrm{~K})$ is within this temperature range. This phenomenon implies that the BFCT sample may contain the $\mathrm{CoFe}_{2} \mathrm{O}_{4}$ inclusions. The 5th TG curve is near horizontal, confirming that the thermal active contribution is very small. Similar curves from the 5th-7th measurements indicate that the phenomena without applied magnetic field can be also well repeated, even though the heating rates are different. If we subtract the 5th TG curve from the 2 nd TG curve, the weight loss from the only contribution of the FM-PM transition will be detected. That is how to deduct the influence of thermal active to weight loss.

To detect the sensitivity of this method, some relevant tests were also done. Fig. 5 shows the weight loss and the DTMG curves of the $\mathrm{ZrO}_{2}-x$ wt. $\% \mathrm{CoFe}_{2} \mathrm{O}_{4}(x=0.5,1,3,6$, 13 and 100), in the same conditions of nitrogen atmosphere at a heating rate of $20 \mathrm{~K} \mathrm{~min}^{-1}$ with a $0.02 \mathrm{~T}$ applied field. Under the magnetic field, weight loss from the thermal active contribution has been automatically deducted. Because the first heating process is easily influenced by the initial condition, each weight loss curve chosen to discuss corresponds to the second heating process of the samples. Since $\mathrm{ZrO}_{2}$ is not a magnetic material, weight loss after deduction of the thermal active contribution should be derived from the FM-PM transition of the $\mathrm{CoFe}_{2} \mathrm{O}_{4}$ phase. From Fig. 5, we can acquire three conclusions: 1 ) even though the weight fraction of $\mathrm{CoFe}_{2} \mathrm{O}_{4}$ changes in samples, the FMPM transition positions of the samples are nearly invariable $(\sim 721 \mathrm{~K}) ; 2)$ in samples, the lower weight fraction of the $\mathrm{CoFe}_{2} \mathrm{O}_{4}$ exists, and the smaller variation of weight loss is observed; 3 ) the accuracy of the DTMG measurement experimentally can reach $\sim 0.5$ wt.\%. Intriguingly, according to the peak area from the DTMG curves, weight loss of $\mathrm{CoFe}_{2} \mathrm{O}_{4}$ and $\mathrm{ZrO}_{2}-13$ wt. $\% \mathrm{CoFe}_{2} \mathrm{O}_{4}$ is about $0.955 \%$ and $0.128 \%$, respectively. The value of $0.128 \% / 0.955 \%$ is approximate $13.4 \%$, consistent with the weight fraction

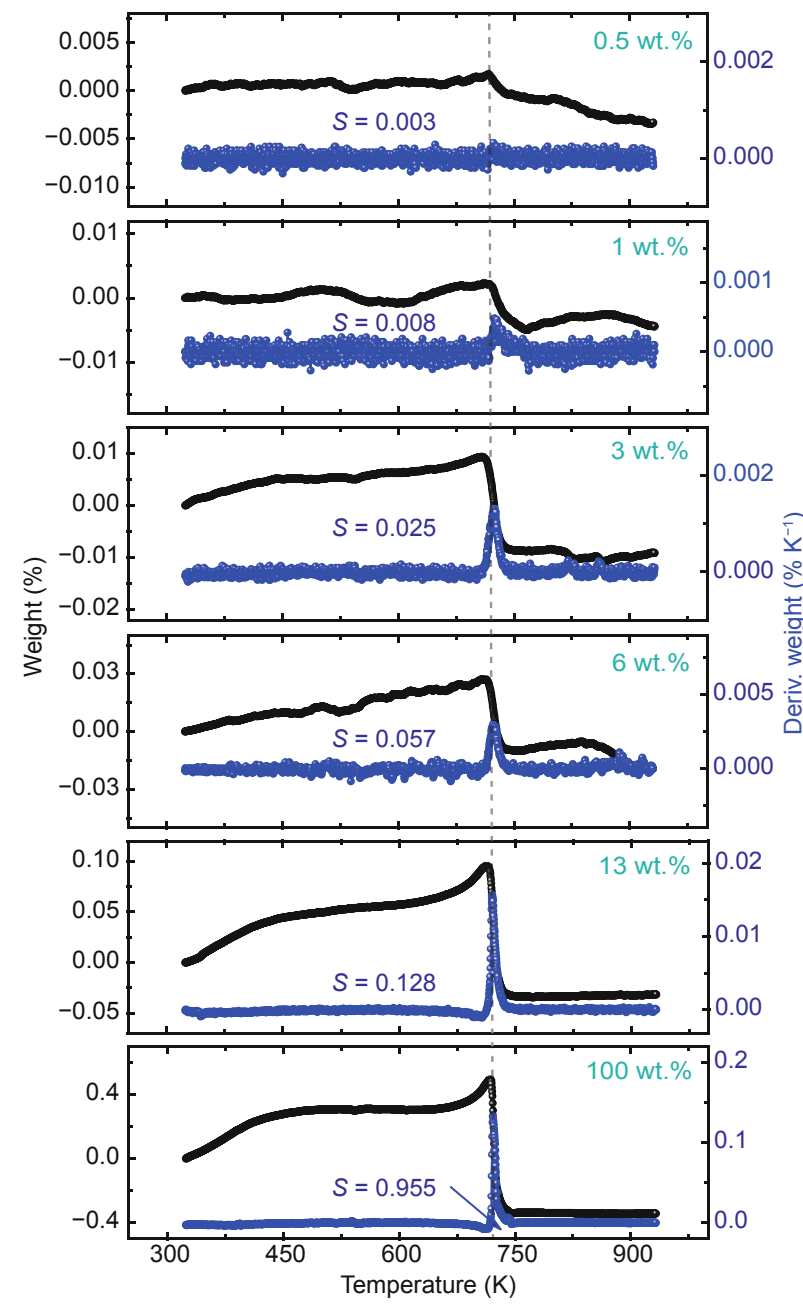

Figure 5 Weight loss and the DTMG curves of the $\mathrm{ZrO}_{2}-x$ wt. $\% \mathrm{CoFe}_{2} \mathrm{O}_{4}$ $(x=0.5,1,3,6,13$ and 100), in the same conditions of nitrogen atmosphere at a heating rate of $20 \mathrm{~K} \mathrm{~min}^{-1}$ with a $0.02 \mathrm{~T}$ applied field. Weight loss from the thermal active contribution has been automatically deducted. The peak area $(S)$ calculated from the DTMG curve is also shown.

of $\mathrm{CoFe}_{2} \mathrm{O}_{4}$ in $\mathrm{ZrO}_{2}-13$ wt.\% $\mathrm{CoFe}_{2} \mathrm{O}_{4}$. More importantly, this way also adapts to other $\mathrm{ZrO}_{2}-x$ wt.\% $\mathrm{CoFe}_{2} \mathrm{O}_{4}$ samples. These results indicate that it is feasible to quantify the weight ratio of $\mathrm{CoFe}_{2} \mathrm{O}_{4}$ inclusions in Aurivillius-type multiferroic ceramics using this method.

Therefore, the DTMG curve of the BFCT ceramic was fitted and decomposed into individual Lorentz components. The weight loss and fitted DTMG curves of the BFCT sample and reference $\mathrm{CoFe}_{2} \mathrm{O}_{4}$ are shown in Fig. 6, which had deducted the thermal active contribution. An obvious peak around $721 \mathrm{~K}$ could confirm the presence of the $\mathrm{CoFe}_{2} \mathrm{O}_{4}$ spinel phase in the BFCT ceramic. According to this peak area, the content of the $\mathrm{CoFe}_{2} \mathrm{O}_{4}$ inclusions can be estimated around 3.6 wt.\% (0.034\%/0.955\%). This 




Figure 6 The calculated weight loss (the thermal active contribution is deducted) and DTMG curves of $\mathrm{BFCT}_{\text {and }} \mathrm{CoFe} \mathrm{O}_{4}$, measured at the heating rate of $20 \mathrm{~K} \mathrm{~min}^{-1}$ with a $0.02 \mathrm{~T}$ magnetic field. The DTMG curves were fitted and decomposed into individual Lorentz components. The quantity and corresponding percentage of the contribution to weight loss from each component were shown too.

value is below the detection limit of XRD, consisting with the above XRD result. In our previous work, it was demonstrated that the $\mathrm{Bi}_{7} \mathrm{Fe}_{2.25} \mathrm{Co}_{0.75} \mathrm{Ti}_{3} \mathrm{O}_{21}$ powder synthesized by the hydrothermal method presents the co-existence of 5- and 4-layer Aurivillius-type perovskite structures [16]. This could account for the rest two peaks at $\sim 687$ and $\sim 710$ $\mathrm{K}$ in Fig. 6. Comparing the contributions from the main Aurivillius phases (85\%) and the second phase inclusions (15\%) to weight loss, we may determine that the observed magnetic contribution to weight loss in sample is mainly attributed to the Aurivillius phases. Assuming that $2 M_{\mathrm{r}}$ and $M_{\mathrm{s}}$ are directly proportional to the weight fraction of the inclusions, $3.6 \mathrm{wt}$. $\%$ of $\mathrm{CoFe}_{2} \mathrm{O}_{4}$ (considering $2 \mathrm{M}_{\mathrm{r}}$ $\sim 53 \mathrm{emu} \mathrm{g}^{-1}$ and $M_{\mathrm{s}} \sim 79 \mathrm{emu} \mathrm{g}^{-1}$ [21]) at RT would give a $2 M_{\mathrm{r}}$ of $1.9 \mathrm{emu} \mathrm{g}^{-1}$ and $M_{\mathrm{s}}$ of $2.8 \mathrm{emu} \mathrm{\textrm {g } ^ { - 1 }}$. The intrinsic $2 M_{\mathrm{r}}$ and $M_{\mathrm{s}}$ of the Aurivillius phases at RT can be estimated around 0.5 and $4.9 \mathrm{emu} \mathrm{g}^{-1}$, respectively, by deducting the contribution of the $\mathrm{CoFe}_{2} \mathrm{O}_{4}$ inclusions. Therefore, we can assert that although the BFCT sample contains $3.6 \mathrm{wt} . \%$ of unwanted $\mathrm{CoFe}_{2} \mathrm{O}_{4}$ inclusions, it has intrinsic ferromagnetism. In addition, we found that this method for the detection and quantification of second phase also adapts to other Aurivillius multiferroic materials, which will be shown in elsewhere.

In addition, the intrinsic FE polarization of the BFCT was confirmed. Fig. 7a presents $P$-E hysteresis loops measured at RT under different applied fields. Remanent polarization $\left(2 P_{\mathrm{r}}\right)$ and coercive field $\left(2 E_{\mathrm{c}}\right)$ measured under the field of $130 \mathrm{kV} \mathrm{cm}^{-1}$ are approximate $14 \mu \mathrm{C} \mathrm{cm}^{-2}$ and 130
$\mathrm{kV} \mathrm{cm}{ }^{-1}$, respectively, which are comparable to $\mathrm{Bi}_{4} \mathrm{Ti}_{3} \mathrm{O}_{12}$ $\left(\sim 15 \mu \mathrm{C} \mathrm{cm}{ }^{-2}\right)$ [29] and $\mathrm{Bi}_{5} \mathrm{Fe}_{0.5} \mathrm{Co}_{0.5} \mathrm{Ti}_{3} \mathrm{O}_{15}\left(\sim 13 \mu \mathrm{C} \mathrm{cm}{ }^{-2}\right)$ [11]. In Fig. $7 \mathrm{~b}, 2 P_{\mathrm{r}}$ increases when increasing the driving electric field. However, the $P-E$ loops are still far from saturation (limited by the instrument or by the sample breakdown). This phenomenon is in very good agreement with the previous report [11]. To identify a possibility of artificial polarization from the leakage current, the pulsed polarization PUND measurement was performed and the results are also shown in Fig. $7 \mathrm{~b}$. The pulsed remanent polarization $\Delta P$ (switched polarization - non-switched polarization) [30] is consistent with $2 P_{\mathrm{r}}$ determined from the $P-E$ loops. This result indicates that the leakage current contribution is very small and confirms the existence of intrinsic FE polarization in the specimen.

\section{CONCLUSION}

In summary, we developed a comprehensive and reliable method to detect and analyse ferromagnetic inclusions in multiferroic ceramics. The measurement accuracy of the DTMG method experimentally can reach $\sim 0.5$ wt.\%, far below the detection limit of XRD. Furthermore, we demonstrated its application to the analysis of the BFCT ceramic, in which the $\mathrm{CoFe}_{2} \mathrm{O}_{4}$ secondary phase was identified and the concentration was estimated to be $\sim 3.6 \mathrm{wt} . \%$. Significantly, the room-temperature and intrinsic multiferroic properties from the main Aurivillius phases were verified, suggesting that the sample is a new single-phase multiferroic material. 

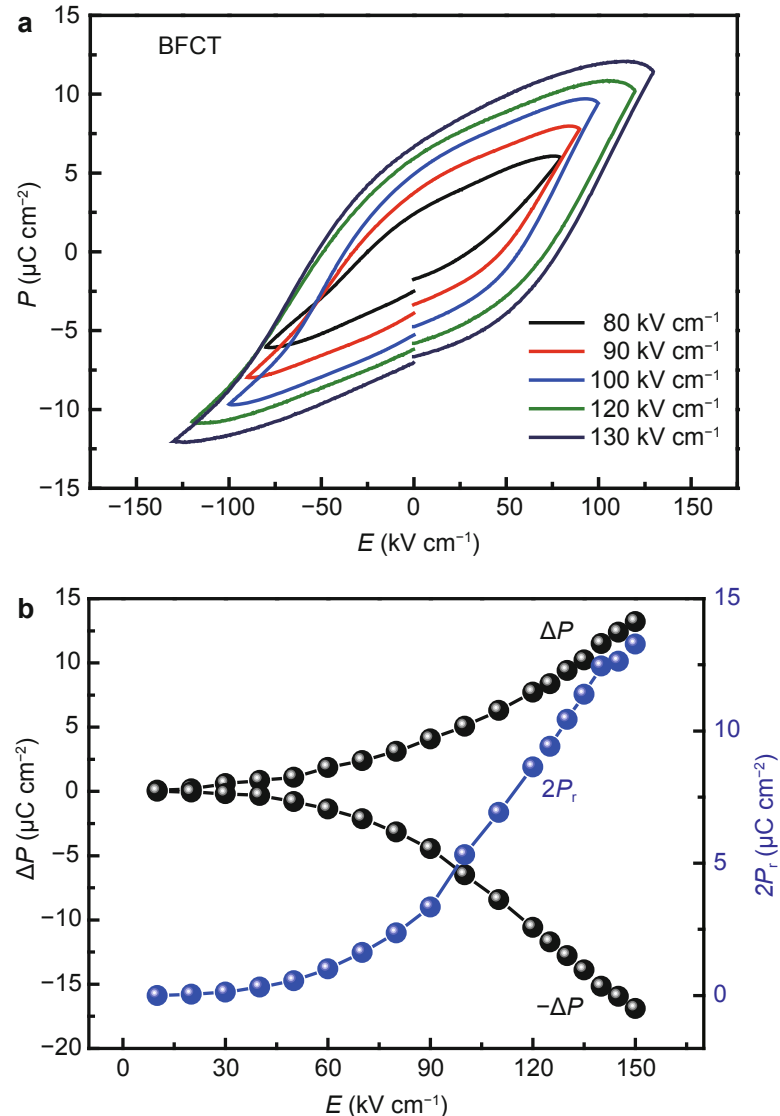

Figure 7 Room temperature ferroelectric property of the BFCT ceramic. (a) $P$ - $E$ hysteresis loops of the BFCT ceramic under different applied fields. (b) $\Delta P$ from PUND measurement and $2 P_{\mathrm{r}}$ from the $P-E$ loops of $\mathrm{BFCT}$ at RT.

Received 26 August 2015; accepted 28 September 2015; published online 16 October 2015

1 Spaldin NA, Cheong SW, Ramesh R. Multiferroics: past, present, and future. Phys Today, 2010, 63: 38-43

2 Hill NA. Why are there so few magnetic ferroelectrics? J Phys Chem B, 2000, 104: 6694-6709

3 Eerenstein W, Mathur ND, Scott JF. Multiferroic and magnetoelectric materials. Nature, 2006, 442: 759-765

4 Krzhizhanovskaya M, Filatov S, Gusarov V, et al. Aurivillius phases in the $\mathrm{Bi}_{4} \mathrm{Ti}_{3} \mathrm{O}_{12} / \mathrm{BiFeO}_{3}$ system: thermal behaviour and crystal structure. Z Anorg Allge Chem, 2005, 631: 1603-1608

5 Zhao H, Kimura H, Cheng Z, et al. Large magnetoelectric coupling in magnetically short-range ordered $\mathrm{Bi}_{5} \mathrm{Ti}_{3} \mathrm{FeO}_{15}$ film. Sci Rep, 2014, 4: 5255

6 Li XN, Ju Z, Li F, et al. Visible light responsive $\mathrm{Bi}_{7} \mathrm{Fe}_{3} \mathrm{Ti}_{3} \mathrm{O}_{21}$ nanoshelf photocatalysts with ferroelectricity and ferromagnetism. J Mater Chem A, 2014, 2: 13366-13372

7 Wang JL, Fu ZP, Peng RR, et al. Low magnetic field response single-phase multiferroics under high temperature. Mater Horiz, 2015, 2: $232-236$

8 Yuan B, Yang J, Chen J, et al. Magnetic and dielectric properties of Aurivillius phase $\mathrm{Bi}_{6} \mathrm{Fe}_{2} \mathrm{Ti}_{3-2 x} \mathrm{Nb}_{x} \mathrm{Co}_{x} \mathrm{O}_{18}(0 \leqslant x \leqslant 0.4)$. Appl Phys Lett, 2014, 104: 062413
9 Sun SJ, Wang GP, Huang Y, et al. Structural transformation and multiferroic properties in Gd-doped $\mathrm{Bi}_{7} \mathrm{Fe}_{3} \mathrm{Ti}_{3} \mathrm{O}_{21}$ ceramics. RSC Adv, 2014, 4: 30440-30446

10 Mao XY, Sun H, Wang W, et al. Ferromagnetic, ferroelectric properties, and magneto-dielectric effect of $\mathrm{Bi}_{4.25} \mathrm{La}_{0.75} \mathrm{Fe}_{0.5} \mathrm{Co}_{0.5} \mathrm{Ti}_{3} \mathrm{O}_{15}$ ceramics. Appl Phys Lett, 2013, 102: 072904

11 Mao XY, Wang W, Chen XB, et al. Multiferroic properties of layer-structured $\mathrm{Bi}_{5} \mathrm{Fe}_{0.5} \mathrm{Co}_{0.5} \mathrm{Ti}_{3} \mathrm{O}_{15}$ ceramics. Appl Phys Lett, 2009, 95: 082901

12 Schmidt M, Amann A, Keeney L, et al. Absence of evidence not equal evidence of absence: statistical analysis of inclusions in multiferroic thin films. Sci Rep, 2014, 4: 5712

13 Palizdar M, Comyn TP, Ward MB, et al. Crystallographic and magnetic identification of secondary phase in orientated $\mathrm{Bi}_{5} \mathrm{Fe}_{0.5} \mathrm{Co}_{0.5^{-}}$ $\mathrm{Ti}_{3} \mathrm{O}_{15}$ ceramics. J Appl Phys, 2012, 112: 073919

14 Williams DB, Papworth AJ, Watanabe M. High resolution X-ray mapping in the STEM. J Electron Microsc, 2002, 51: S113-S126

15 Moskalewicz R, Zych W. Application of the DTMG-DTA(M) technique for the curie-point and crystallization temperature determinature of $\mathrm{Fe}_{80-x} \mathrm{Mn}_{x} \mathrm{~B}_{20}$ amorphous-alloys. Phys Status Solidi A-Appl Res, 1986, 97: K43-K48

16 Li XN, Zhu Z, Feng L, et al. Facile route to prepare grain-oriented multiferroic $\mathrm{Bi}_{7} \mathrm{Fe}_{3-x} \mathrm{Co}_{x} \mathrm{Ti}_{3} \mathrm{O}_{21}$ ceramics. J Eur Ceram Soc, 2015, 35: 3437-3443

17 Keeney L, Kulkarni S, Deepak N, et al. Room temperature ferroelectric and magnetic investigations and detailed phase analysis of Aurivillius phase $\mathrm{Bi}_{5} \mathrm{Ti}_{3} \mathrm{Fe}_{0.7} \mathrm{Co}_{0.3} \mathrm{O}_{15}$ thin films. J Appl Phys, 2012, 112: 024101

18 Srinivas A, Kumar MM, Suryanarayana SV. Investigation of dielectric and magnetic nature of $\mathrm{Bi}_{7} \mathrm{Fe}_{3} \mathrm{Ti}_{3} \mathrm{O}_{21}$. Mater Res Bull, 1999, 34: 989-996

19 Lu SZ, Qi XD. Magnetic and dielectric properties of nanostructured $\mathrm{BiFeO}_{3}$ prepared by sol-gel method. J Am Ceram Soc, 2014, 97: 2185-2194

20 Zi Z, Sun Y, Zhu Y, et al. Synthesis and magnetic properties of $\mathrm{CoFe}_{2} \mathrm{O}_{4}$ ferrite nanoparticles. J Magn Magn Mater, 2009, 321: 1251-1255

21 Nlebedim IC, Snyder JE, Moses AJ, et al. Effect of deviation from stoichiometric composition on structural and magnetic properties of cobalt ferrite, $\mathrm{Co}_{x} \mathrm{Fe}_{3-x} \mathrm{O}_{4}(x=0.2$ to 1.0). J Appl Phys, 2012, 111: 07D704

22 Suzuki T, Nagai H, Nohara M, et al. Melting of antiferromagnetic ordering in spinel oxide $\mathrm{CoAl}_{2} \mathrm{O}_{4}$. J Phys Conden Matter, 2007, 19: 145265

23 Grave ED, Persoons R, Vandenberghe R, et al. Mössbauer study of the high-temperature phase of Co-substituted magnetites, $\mathrm{Co}_{x} \mathrm{Fe}_{3-x} \mathrm{O}_{4}$. Phys Rev B, 1993, 47: 5881-5893

24 Fujii T, de Groot FMF, Sawatzky GA. In situ XPS analysis of various iron oxide films grown by $\mathrm{NO}_{2}$-assisted molecular-beam epitaxy. Phys Rev B, 1999, 59: 3195-3202

25 Mitra S, Das S, Mandal K, et al. Synthesis of a $\alpha-\mathrm{Fe}_{2} \mathrm{O}_{3}$ nanocrystal in its different morphological attributes: growth mechanism, optical and magnetic properties. Nanotechnology, 2007, 18: 275608

26 Muralidharan R, Dix D, Skumryev V, et al. Synthesis, structure, and magnetic studies on self-assembled $\mathrm{BiFeO}_{3}-\mathrm{CoFe}_{2} \mathrm{O}_{4}$ nanocomposite thin films. J Appl Phys, 2008, 103: 07E301

27 Zheng H, Wang J, Mohaddes-Ardabili L, et al. Three-dimensional heteroepitaxy in self-assembled $\mathrm{BaTiO}_{3}-\mathrm{CoFe}_{2} \mathrm{O}_{4}$ nanostructures. Appl Phys Lett, 2004, 85: 2035-2037

28 Li J, Levin I, Slutsker J, et al. Self-assembled multiferroic nanostructures in the $\mathrm{CoFe}_{2} \mathrm{O}_{4}-\mathrm{PbTiO}_{3}$ system. Appl Phys Lett, 2005, 87: 072909

29 Mao XY, He JH, Zhu J, et al. Structural, ferroelectric, and dielectric 
properties of vanadium-doped $\mathrm{Bi}_{4-x / 3} \mathrm{Ti}_{3-x} \mathrm{~V}_{x} \mathrm{O}_{12}$. J Appl Phys, 2006, 100: 044104

30 Hu GD, Cheng X, Wu WB, et al. Effects of Gd substitution on structure and ferroelectric properties of $\mathrm{BiFeO}_{3}$ thin films prepared using metal organic decomposition. Appl Phys Lett, 2007, 91: 232909

Acknowledgments This work was supported by the National Basic Research Program of China (2012CB922001), the External Cooperation Program of BIC (211134KYSB20130017) and the Fundamental Research
Funds for the Central Universities (WK2060140014). We are grateful to Dr. Yan-wei Ding of the University of Science and Technology of China for discussion of the measurements.

Author contributions Sun S and Lu Y designed and performed the experiments; Sun S, Peng R and Lu Y analysed the results and wrote the manuscript; Liu C and Fu Z contributed through useful discussion. All authors commented on the manuscript.

Conflict of interest The authors declare that they have no conflict of interest.

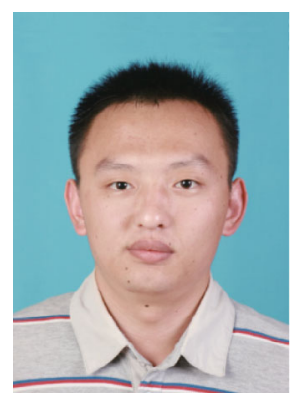

Shujie Sun is currently a PhD candidate of materials science at the Department of Materials Science and Engineering, University of Science and Technology of China (USTC), Hefei, China. His scientific interests are mainly focused on the structure and properties of complex oxides materials.

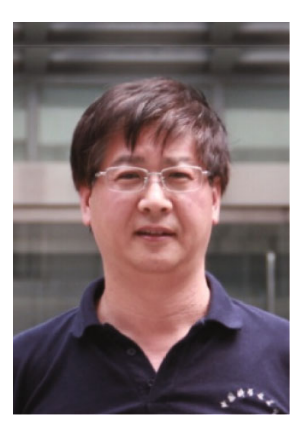

Yalin Lu is a full professor of the USTC. He is now Director of National Synchrotron Radiation Laboratory, Deputy Director of Hefei Science Center. Before joining the USTC, he was a visiting professor at Lawrence Berkeley National Laboratory (1996-1998), a research professor in electrical engineering at Tufts University (1998-2000) and a full professor in physics at the US Air Force Academy (2003-2012). His research group in the USTC works on materials for energy conversion, THz optics and materials, optoelectronics, and complex oxides materials physics.

中文摘要 判断新的材料是否是一个室温单相多铁性材料需要认真的鉴定评价, 特别是对于Aurivillius相多铁材料. 这类材料中易生成 微量的具有铁磁性的杂质, 从而混淆对其本征磁性能的判断. 本论文介绍了一种磁失重方法, 并应用该方法判断和量化了Aurivillius 相 层状结构陶瓷 $\mathrm{Bi}_{7} \mathrm{Fe}_{2.25} \mathrm{Co}_{0.75} \mathrm{Ti}_{3} \mathrm{O}_{21}$ 中的磁性杂质. 该方法的测量精度远高于X-射线仪器的精度, 能够辨别出含量仅为 $0.5 \%$ 重量的杂质. 最 终结果表明陶瓷 $\mathrm{Bi}_{7} \mathrm{Fe}_{2.25} \mathrm{Co}_{0.75} \mathrm{Ti}_{3} \mathrm{O}_{21}$ 中的磁性杂质是尖晶石相 $\mathrm{CoFe}_{2} \mathrm{O}_{4}$, 其含量约占总质量的 $3.6 \%$. 通过该方法同时确定了该陶瓷的室温 固有磁性. 本研究不仅展示了磁失重方法, 而且通过固有磁性和固有铁电性的鉴定, 证明了该陶瓷是一种新的室温单相多铁性材料. 